\title{
AÇÃO DOCENTE E INCLUSÃO ESCOLAR: Uma reflexão sobre pesquisa e processos de escolarização
}

\author{
Gilvane Belem Correia \\ Claudio Roberto Baptista ${ }^{(*)}$
}

O debate sobre a escolarização das pessoas com deficiência é um fenômeno que tem assumido relevância nos últimos anos. Em sintonia com esse debate, o presente texto tem como objetivo a análise relativa ao avanço dessa escolarização no ensino comum e as implicações que envolvem o currículo e, de modo particular, a ação docente.

A concepção que sustentou, historicamente, a separação entre a escolarização prevista em espaços exclusivos da educação especial e aquela desenvolvida na escola comum estava associada à crença na existência de padrões estáticos e regulares dos fenômenos humanos. De acordo com essa compreensão, a deficiência seria uma condição imutável e um atributo único e exclusivo daquele sujeito em específico. A crise dessa concepção associada à educação especial vem ocorrendo, no Brasil, ao longo das três últimas décadas, em sintonia com movimentos internacionais, sendo um dos mais recentes a Convenção Internacional sobre os Direitos das Pessoas com Deficiência (ONU, 2007). A definição de deficiência enfatizada pela referida Convenção corrobora uma perspectiva social e fortalece o direito à educação das pessoas com deficiência no "sistema educacional geral" (ONU, 2007):

Reconhecendo que a deficiência é um conceito em evolução e que a deficiência resulta da interação entre pessoas com deficiência e as barreiras devidas às atitudes e ao ambiente que impedem a plena e efetiva participação dessas pessoas na sociedade em igualdade de oportunidades com as demais pessoas (ONU, 2007).

Ao assinar o protocolo facultativo da referida Convenção (ONU, 2007) e incorporar seu texto à legislação brasileira como Emenda Constitucional por meio do Decreto Legislativo $\mathrm{n}^{\circ} 186$ (BRASIL, 2008a), que aprovou o seu texto em 09 de julho de 2008, e pelo Decreto do Poder Executivo $\mathrm{n}^{\mathrm{o}}$ 6.949, de 25 de agosto de 2009, o Brasil se compromete a reconhecer "o direito das

\footnotetext{
${ }^{(*}$ Gilvane Belem Correia. Pedagoga da Universidade Federal do Pampa, atuando no Núcleo de Desenvolvimento Educacional do Campus São Borja. Docente da rede estadual do Rio Grande do Sul. Mestrado em Educação pela Universidade Federal do Rio Grande do Sul.E-mail: gilvanebc@gmail.com.

Claudio Roberto Baptista. Professor Titular na área de Educação Especial, no Departamento de Estudos Básicos, na Faculdade de Educação e no Programa de Pós-Graduação em Educação, na Universidade Federal do Rio Grande do Sul. Doutorado em Educação - Universita degli Studi di Bologna (1996) e Pos-doutorado pela Università di Roma 'Foro Italico' (2015). E-mail: baptistacaronti@ yahoo.com.br.
} 
pessoas com deficiência à educação" e a assegurar "sistema educacional inclusivo em todos os níveis, bem como o aprendizado ao longo de toda a vida" (BRASIL, 2009, art. 24). Para efetivar esse direito, assume o que é imputado aos Estados Partes no âmbito da Convenção:

a) As pessoas com deficiência não sejam excluídas do sistema educacional geral sob alegação de deficiência e que as crianças com deficiência não sejam excluídas do ensino primário gratuito e compulsório ou do ensino secundário, sob alegação de deficiência;

b) As pessoas com deficiência possam ter acesso ao ensino primário inclusivo, de qualidade e gratuito, e ao ensino secundário, em igualdade de condições com as demais pessoas na comunidade em que vivem;

c) Adaptações razoáveis de acordo com as necessidades individuais sejam providenciadas;

d) As pessoas com deficiência recebam o apoio necessário, no âmbito do sistema educacional geral, com vistas a facilitar sua efetiva educação;

e) Medidas de apoio individualizadas e efetivas sejam adotadas em ambientes que maximizem o desenvolvimento acadêmico e social, de acordo com a meta de inclusão plena (BRASIL, 2009, art. 24).

Como analisa Cury (2002, p. 246), para que um direito seja garantido é preciso "que ele esteja inscrito em lei de caráter nacional”. Para esse autor, a educação é princípio fundante da cidadania.

Duarte (2007) lembra que o direito à educação, expresso no art. $6^{\circ}$ da Constituição Federal de 1988, possui uma dimensão que ultrapassa o atendimento a interesses meramente individuais, mas que se constitui em interesse da comunidade, considerado como bem comum, "já que representa a busca pela continuidade de um modo de vida que, deliberadamente, se escolhe preservar" (DUARTE, 2007. p. 697). Essa autora considera que a garantia dos direitos sociais, por parte do Estado, envolve, necessariamente, prover meios para que a universalidade pretendida atinja os grupos historicamente alijados desses direitos.

Contudo, não obstante o reconhecimento expresso da universalidade dessa categoria de direitos, a sua implementação demanda a escolha de alvos prioritários, ou seja, grupos de pessoas que se encontram em uma mesma posição de carência ou vulnerabilidade. Isso porque o objetivo dos direitos sociais é corrigir desigualdades próprias das sociedades de classe, aproximando grupos ou categorias marginalizadas.

Como consequência, tem-se que o poder público, titular do dever jurídico correlato ao direito à educação, conforme expressamente previsto no artigo 205 da CF/88, deverá organizar-se para fornecer os serviços educacionais a todos, de acordo com os princípios estatuídos na 
Constituição, sempre no sentido de ampliar cada vez mais as possibilidades de que todos venham a exercer igualmente este direito (DUARTE, 2007, p. 698).

Entre os diversos grupos historicamente alijados do direito à educação encontram-se as pessoas com deficiência, das quais se propõe tratar este artigo. A Lei de Diretrizes e Bases da Educação Nacional no 9394/1996, ao afirmar os pressupostos da Constituição Federal de 1988 (BRASIL, 1988), no sentido de atender à ampliação de possibilidades de exercício do direito à educação referida por Duarte (2007), introduz uma nova concepção de educação especial. Essa modalidade de educação passa a compor a educação geral com a função de oferecer-lhe os apoios necessários para que a escolarização dos sujeitos com deficiência ocorra nas classes de ensino comum, em escolas regulares. A educação especial assume o oferecimento de "serviços de apoio especializado, na escola regular, para atender às peculiaridades da clientela de educação especial" (BRASIL, 1996, art. 58, parágrafo $1^{\circ}$ ).

Em 2008, é lançada a Política Nacional de Educação Especial na Perspectiva da Educação Inclusiva (BRASIL, 2008b), que apresenta as diretrizes para o processo de inclusão de estudantes com deficiência no ensino comum e dá corpo ao apoio especializado anunciado genericamente pela LDBEN no 9394/1996, denominando-o de atendimento educacional especializado (AEE). Essa política propõe para a educação especial, por meio do AEE, a função de prover "apoios" para eliminar ou minimizar barreiras que obstruem o acesso dos estudantes com deficiência ao ensino comum.

Para regulamentar o que define a Carta Magna e a Política Nacional de Educação Especial na Perspectiva da Educação Inclusiva quanto ao Atendimento Educacional Especializado (AEE), foi publicado, em 2008, o Decreto 6.571/2008 (BRASIL, 2008c), posteriormente substituído pelo Decreto 7.611/2011. Essa normativa traz, em seu art. $2^{\circ}$, parágrafo $1^{\circ}$, a definição de AEE:

Conjunto de atividades, recursos de acessibilidade e pedagógicos organizados institucional e continuamente, prestado das seguintes formas:

I. complementar à formação dos estudantes com deficiência, transtornos globais do desenvolvimento, como apoio permanente e limitado no tempo e na frequência dos estudantes às salas de recursos multifuncionais; ou

II. suplementar à formação de estudantes com altas habilidades ou superdotação (BRASIL, 2011). 
Ao conceber o AEE como apoio complementar ou suplementar e a educação especial como transversal (art. $3^{\circ}$, inciso II) a todos os níveis, etapas e modalidades, anuncia-se uma nova concepção de educação especial, que busca constituir-se sob diferentes formas de "apoio".

No entanto, a crença na escolarização das pessoas com deficiência pode ser considerada como um dos nós críticos da Política Nacional de Educação Especial na Perspectiva da Educação Inclusiva (BRASIL, 2008a), pois envolve a superação de visões já consolidadas de deficiência e de educação escolar. Vasques e Baptista (2014, p. 659) afirmam que:

Na educação especial, a escolarização não é apenas uma proposição recente e tardia, mas se anuncia como território de controvérsias ao evocar polarizações que nem sempre consideram que a trajetória escolar, na escolar regular, seria uma meta defensável.

Acredita-se que um dos movimentos que podem contribuir para assegurar o direito das pessoas com deficiência à educação comum "em igualdade de condições com as demais pessoas" (BRASIL, 2009) seja o investimento em estudos que discutam aspectos relacionados à escolarização desses sujeitos, contribuindo para a desmitificação de crenças que relacionam deficiência a incapacidade.

Com o objetivo de aprofundar essa discussão, destacamos alguns autores que foram a campo verificar como está ocorrendo a escolarização dos sujeitos com deficiência no ensino comum. Os trabalhos selecionados compõem a base de uma pesquisa de cunho qualitativo e bibliográfico desenvolvida como dissertação de mestrado ${ }^{1}$, no âmbito do Programa Observatório da Educação, com apoio da CAPES/INEP.

Os estudos que constituíram a base bibliográfica da pesquisa forneceram uma amostra mais ampla, constituindo-se como parte da confirmação do problema. A busca foi realizada no Portal de Teses e Dissertações da Capes, Portal da Anped Nacional e Anped Sul, Portal Redalyc e Biblioteca Brasileira Digital de Teses e Dissertações, tendo como referência temporal o período de 2009 a 2015. Os descritores utilizados na busca foram: educação especial, educação inclusiva, currículo, adaptações curriculares, adequações curriculares, flexibilização curricular, escolarização, deficiência, aprendizagem, conhecimento.

De modo geral, duas grandes questões emergiram da pesquisa: a reiterada constatação de que os sujeitos público-alvo da educação especial inseridos no ensino comum não estão, efetivamente, participando das experiências de aprendizagem às quais os demais alunos têm (ou

\footnotetext{
${ }_{1}^{1}$ Pesquisa, concluída em julho de 2016, que teve por objetivo discutir a relação entre educação especial e currículo, permeada pelos conceitos deficiência, conhecimento e aprendizagem.
} 
deveriam ter) acesso; e a inferência de que a suposta impossibilidade de sua participação e a consequente não aprendizagem estariam diretamente relacionadas à formação precária dos docentes.

A questão recorrente nos trabalhos selecionados diz respeito à promoção da efetiva participação dos estudantes com deficiência na sala de aula, em razão da dificuldade de prover as adaptações necessárias. Muitos estudos, dentre os quais destacamos Pletsch (2009), Costa (2009), Lopes (2010), Cardoso (2011), Pletsch e Glat (2011), Almeida (2012), Anjos (2012), Campos (2012), Costa (2012), Anselmo (2012), Dantas (2014), Mendonça (2014), relatam as incertezas presentes no cotidiano dos profissionais que participaram de suas pesquisas e atribuem tal situação à incipiente formação para conduzir as práticas pedagógicas de modo a envolver todos os alunos de acordo com suas características e possibilidades individuais. Caiado, Martins e Antonio (2009), assim como Mendes, Almeida e Toyoda (2011), apontam a necessidade de reflexão sobre formação de professores e práticas pedagógicas desenvolvidas nas classes denominadas "inclusivas".

\section{A ATUAÇÃO DOCENTE E O SEU CONTEXTO DE SIGNIFICAÇÕES}

A presente análise, ao se apoiar no pensamento sistêmico como referência teóricometodológica, considera que pode ser simplificadora a interpretação que responsabiliza unicamente um ou outro ator do processo educacional, porque não se identifica no cotidiano da escola a observância das orientações contidas nos documentos oficiais de uma política. Ao se balizar a análise tendo como referência o pensamento sistêmico, busca-se contemplar os fenômenos desde uma perspectiva inter-relacional e interdependente, direcionando o olhar da pesquisa para as relações que se estabelecem no processo educativo e os significados nelas compartilhados. Bateson (1986, p. 25) lembra que "toda comunicação necessita de um contexto, que sem contexto não há significado", e refuta a previsibilidade como apanágio da ciência, ao considerar que os eventos são resultado de uma "história" que foi e está sempre sendo construída com grande participação do acaso.

Maturana e Varela (2011), ao explicarem o conhecimento como produto do acoplamento estrutural entre organismo e ambiente, consideram que ao observador, neste caso o pesquisador, é possível ver relações que não são passíveis de serem habitualmente percebidas pelos organismos em sua interação com o meio. O organismo atua no mundo se valendo de sua estrutura de aquisições e significações selecionadas a partir de suas relações com o meio, não lhe sendo possível enxergar todas as alternativas de ação e avaliar qual seria aquela mais adequada. Portanto, para Maturana e 
Varela (2011), organismo e meio são sistemas separados que estabelecem relações de mútuo acoplamento e se modificam reciprocamente.

\begin{abstract}
Nenhum desses dois domínios possíveis de descrição é problemático em si. Ambos são necessários para o pleno entendimento de uma unidade. É o observador quem os correlaciona a partir de sua perspectiva externa. É ele quem reconhece que a estrutura do sistema determina suas interações, ao especificar que configurações do meio podem desencadear no sistema mudanças estruturais. É ele quem reconhece que o meio não especifica ou instrui as mudanças estruturais do sistema (MATURANA; VARELA, 2011, p. 151).
\end{abstract}

Considera-se ser essa uma perspectiva válida para a pesquisa acadêmica direcionada ao trabalho docente diante da escolarização de pessoas com deficiência no ensino comum.

Magalhães e Souza (2012) assinalam que "a definição dos professores(as) como problema" ocorre na literatura educacional nacional e internacional da atualidade, defendida tanto por autores mais alinhados com os interesses do capital como por aqueles que estão preocupados com a qualidade de sua atuação. As autoras consideram importante essa discussão, mas se baseiam em Sacristán (2002) para recomendar cautela. Este autor afirma que "a maior parte da investigação sobre a formação dos professores é uma investigação enviesada, parcial, desestruturada, descontextualizada e não entra na essência dos problemas" (SACRISTÁN, 2002, p. 22). Essa veemente afirmação está relacionada com a problematização por ele proposta e direcionada à pesquisa em educação quando esta analisa os professores. $\mathrm{O}$ autor faz três advertências a partir de algumas "suspeitas": a primeira delas é que, enquanto os professores trabalham, os pesquisadores discursam sobre suas práticas. Estes não falam de suas práticas, mas da prática de outros que não podem falar. A segunda diz respeito ao falar sobre os professores desde um lugar que desconhece sua prática e que o faz de perspectivas muito distintas, pois o autor considera que as atividades de professores universitários e professores do ensino fundamental são muito diferentes, inclusive no que diz respeito a status, logo, uma análise de um sobre outro é considerada por ele como suspeita. A terceira, por fim, se refere à preferência pela temática "professores" quando se trata de investigações científicas na área da educação, ao que o autor contrapõe outras áreas profissionais, a exemplo de militares que não estudam sobre outros militares ou de sacerdotes que estudam sobre Deus e não sobre outros sacerdotes. Diante de tais suspeitas, Sacristán (2002) conclui, entre outras coisas, que:

[...] a forma de ser dos professores é uma forma de comportamento cultural, não uma forma adquirida nos cursos de formação. Isto significa que é muito importante atender às raízes culturais das quais se nutrem os professores, para entender como atuam e por que atuam e como queremos que devam atuar. [...] E dizer que um professor se nutre das raízes culturais e 
não da ciência nos obriga a considerar os ambientes de aprendizagem, os contextos nos quais eles surgem e as condições de trabalho [...] (p. 27).

Ainda, o autor cita Bourdieu para aplicar o conceito de habitus como preponderante aos motivos e à ciência como definidores da prática educativa escolar: "O habitus é cultura, é costume, é conservadorismo, mas é, também, continuidade social, e, como tal, pode produzir outras práticas diferentes das existentes" (SACRISTÁN, 2002, p. 27).

Arroyo (1999) considera "mecânica" a lógica que vincula os problemas de qualidade da escola com a atuação dos professores, pensando que tal situação possa ser revertida unicamente com o investimento na formação prévia desses profissionais. Esse autor critica a ideia dominante de que toda a inovação carece de um investimento prévio e longo de preparação, uma visão "precedente" que se dedica a treinar para a "intervenção sempre adiada por falta de preparo adequado" (ARROYO, 1999, p. 146). Defende, ainda, que tal visão é responsável por se pensar possível "formar" os professores para executar "tarefas" diferentes toda vez que essas são definidas como necessárias no âmbito das políticas educacionais. Tal pressuposto equivale, segundo Arroyo (1999), a considerar esses profissionais como simples "tarefeiros".

A visão tradicional parece supor que nosso papel muda em cada conjuntura, o que reflete uma visão pobre da educação básica e dos educadores. Reflete os estragos que a visão tecnicista fez na concepção de educação básica e na figura social de seus profissionais e de sua formação. Reflete, ainda, os estragos ocasionados por ela nas políticas de formação, nos currículos, nos cursos e nas instituições formadoras. A visão tecnicista, utilitária e mercantil desqualificou a educação básica, o papel de seus profissionais e os processos de sua formação, marginalizou o que há de mais permanente - as dimensões históricas que a função de educador acumulou como tarefa social e cultural, como ofício (ARROYO, 1999, p. 147).

A análise dos estudiosos aqui evocados nos mostra que seria necessário reconhecer a complexidade do ofício docente e sua implicação com fenômenos históricos e culturais. Apresentam-se a seguir quatro estudos que também compõem a base da pesquisa supracitada, cujas discussões fornecem elementos para se pensar as dificuldades relacionadas com a escolarização dos sujeitos com deficiência a partir de uma perspectiva que considera a coexistência de múltiplos elementos associados à atuação docente: Costa (2009), Mesquita (2013), Mendonça (2014), Cintra (2014).

Costa (2009) compara professores que possuem formação na área da educação especial com professores que não a possuem e não encontra diferenças no que se refere a suas representações 
sobre inclusão educacional, tampouco em suas práticas pedagógicas. A autora questiona a qualidade da formação ofertada aos primeiros.

A busca por elementos (apontados pela comunidade escolar) que indiquem que um professor é "inclusivo" constitui a pesquisa realizada por Mesquita (2013). O estudo traz relatos sobre como se desenrola a experiência "inclusiva" nas salas de aula pesquisadas. Uma das questões exploradas pela autora é a centralidade ocupada pela escrita na cultura escolar: tudo é baseado na cópia, os alunos são classificados entre os que copiam e os que não copiam. Aparecem também, de forma muito explícita, as "tarefas elementares"2 de que falam Pletsch e Glat (2011, p. 5). Mesquita (2013) conclui que o fato de as mães dos alunos com deficiência considerarem a professora sujeito da pesquisa como "professora inclusiva" está relacionado com a cultura escolar na qual todos estão imersos, com a sua "representação" de escola. Se essa professora está conseguindo fazer com que seus filhos participem, de alguma forma, dessa cultura, então, ela é inclusiva, embora sua prática denuncie uma visão muito tradicional.

Falas da professora pesquisada levam a autora a concluir:

Ora, o que está posto nesse cenário: 1) A certeza de que o fazer escolar só é fazer propriamente escolar quando os elementos como conteúdo, uso do livro didático, das tarefas, do cumprimento do planejamento são efetivamente marcas de que existe um processo de escolarização sendo desenvolvido; 2) a certeza que essa forma de fazer educação não é eficiente para todos os alunos, por isso a necessidade de alterações pedagógico-curriculares, necessidade essa que passa a compor o discurso da escola inclusiva (MESQUITA, 2013, p. 147).

A pesquisadora ressalta que a prática também é um elemento da cultura escolar. A professora tem um planejamento para os alunos ditos "normais" e um outro, individual, para cada um dos alunos com deficiência. Identifica-se, nessa estratégia, a conservação de uma tradição: professor como transmissor, aluno como receptor e conhecimento como aproximação hierárquica entre os dois (MESQUITA, 2013, p. 149). A presença dos alunos com deficiência faz a professora entrar em conflito com essa tradição. O problema não é o aluno com deficiência, mas a forma como a escola está estruturada, de um modo que não consegue dar conta do trabalho com ele. A professora se vê em conflito diante de duas culturas: reprodutora (que historicamente marca a escola) e aquela como tradição nutriente (presente no discurso político e especializado sobre

\footnotetext{
${ }^{2}$ Recortar, colar, pintar, copiar. Ou seja, atividades que não favoreciam o desenvolvimento de habilidades cognitivas mais elaboradas necessárias para a construção de conceitos científicos que envolvem conhecimentos abstratos (por exemplo, a relação entre o signo representado pelo número um e a quantidade que ele representa). (PLETSCH; GLAT, 2011, p. 5).
} 
inclusão) (MESQUITA, 2013, p. 150). Diante de elementos que anunciam a presença de uma cultura escolar que dá sentido à prática pedagógica, a autora faz duas inferências:

1) Enquanto a política curricular inclusiva for compreendida como um modelo a ser seguido e encapsulado na escola, esta e suas práticas continuarão sendo definidas como fracassadas; 2) se a cultura escolar instituída ao longo da história da escolarização é a da exclusão e a cultura que se quer instituir é o seu oposto, a inclusão, é fundamental que as práticas historicamente produzidas sejam compreendidas como elementos de continuidade da nova cultura" (MESQUITA, 2013, p. 151).

Mesquita (2013) defende que a cultura tradicional da escola tem como eixo estruturante os conteúdos, os conhecimentos escolares; e a cultura inclusiva teria como eixo estruturante o reordenamento espaço-tempo.

Outro trabalho que oferece bases para pensar as práticas escolares a partir de relações mais complexas é realizado por Mendonça (2014), por meio de um estudo de caso envolvendo alunos com deficiência intelectual com o objetivo de conhecer as práticas de avaliação da aprendizagem direcionadas a esses sujeitos nos Anos Iniciais do Ensino Fundamental da Rede Municipal de Ensino de Fortaleza - CE. A pesquisa revelou que os professores concebem a avaliação da aprendizagem dos alunos com deficiência intelectual como "registro dos resultados" da aprendizagem, e tais resultados são expressos em relatórios, de forma diferenciada dos demais alunos. Embora essa seja uma estratégia construída na articulação entre os professores do ensino comum e do apoio especializado, compreendida como uma forma de flexibilização curricular, “alguns relatos exprimem o anseio de familiares ou responsáveis por uma avaliação com boletins e notas, usada no cotidiano dos demais alunos, que conferem um padrão de normalidade, com o qual eles gostariam de conviver, mesmo que as notas fossem baixas” (MENDONÇA, 2014, p. 123). Este é um dos trabalhos que também advoga pela "necessidade iminente de formação profissional" para os docentes que "se declaram despreparados, mas não questionaram acerca da influência do tradicionalismo da prática pedagógica sobre as dificuldades para avaliar os alunos com deficiência" (MENDONÇA, 2014, p. 125).

A pesquisa de Cintra (2014) traz, na fala dos entrevistados, a visão de avaliação classificatória, excludente, que se preocupa com a aquisição de conhecimentos na forma mais tradicional dessa aquisição, bem como a preocupação do professor com a cobrança dos pais para que a turma "ande" em termos de conteúdos. Vê-se o professor em conflito entre duas lógicas: já consegue perceber que deve valorizar os avanços individuais, mas ainda se sente preso à visão do currículo como "pista de corrida". 
Esses quatro trabalhos, de forma exemplar, trazem para a cena outras questões presentes no contexto escolar que condicionam a atuação do professor. Pode-se dizer que há uma cultura e uma racionalidade na base do processo pedagógico que funcionam como ponto de convergência entre a tradição que caracteriza a docência e as expectativas das famílias e da sociedade em relação à escola. A atuação do professor é, inegavelmente, relevante para o processo pedagógico, no entanto parece que não pode ser analisada de forma isolada de uma cultura ${ }^{3}$ que lhe confere significado.

Tardif e Lessard (2013) trazem suas contribuições para o processo de análise do trabalho dos professores ao produzirem uma crítica das "visões normativas e moralizantes" da docência. Essas visões, segundo os autores, se interessam pelo que os professores "deveriam fazer" ao invés de se ocuparem do "que eles realmente são e fazem" (TARDIF; LESSARD, 2013, p. 36). A perspectiva defendida por esses autores não significa um desprezo pelos aspectos teóricos que indicam direções à atuação docente, mas considera que é preciso "levar as pesquisas ao campo propriamente dito das práticas cotidianas pelas quais se realiza e se reproduz o processo de trabalho dos atores escolares" (TARDIF; LESSARD, 2013, p. 38). Entendem que as práticas cotidianas guardam em si algumas variáveis do sistema, mas apresentam também muitos desvios, conflitos, contradições que produzem outras configurações não esperadas ou previstas a partir das definições oficiais. Esses autores consideram o ensinar como um "trabalho composto", caracterizado por múltiplas facetas e constituído tanto por questões oriundas de uma tradição, como por aspectos contingentes. A tradição está relacionada com as rotinas, com a reprodução de "ritos" que são aprendidos e significados desde a vivência escolar como alunos. Os aspectos contingentes estão relacionados com as inovações introduzidas na ação docente diante da natureza não previsível de um trabalho, cujo diferencial mais significativo é o de estar relacionado com a interação humana.

Diante das ponderações de Tardif e Lessard (2013), é possível pensar a atuação docente como uma atividade condicionada por um contexto cultural e social:

A organização escolar na qual o trabalho é desenvolvido tampouco é um mundo fechado; ela não é autônoma, mas participa de um contexto social mais global no qual está inscrita. Esse contexto social não é uma abstração sociológica, nem um horizonte longínquo ou situado "fora" da escola. Pelo contrário, tal contexto social está tanto "dentro" quanto "fora" da escola, é ao mesmo tempo individual e coletivo. [...] Nesse sentido, as atividades escolares nunca são fechadas em si mesmas, como uma cadeia de montagem cibernética que gira sobre cilindros num movimento circular: dia após dia, os alunos entram e saem da classe, modificando sem

\footnotetext{
${ }^{3}$ Conjunto dos processos sociais de significação ou, de um modo mais complexo, a cultura abarca o conjunto de processos sociais de produção, circulação e consumo da significação na vida social (CANCLINI, 2009, p. 41).
} 
parar o ritmo escolar, introduzindo pontos de resistência, fazendo com que a escola perca o controle sobre aqueles que ela forma (TARDIF; LESSARD, 2013, p. 44).

É possível estabelecer um diálogo entre Tardif e Lessard (2013) e Meirieu (2002) ao se cogitar que a atuação docente tem muito de arte, de criação, de inventividade. Nesse sentido, Tardif e Lessard (2013, p. 46) percebem o surgimento de um olhar da pesquisa sobre a docência que a vê "como um 'artesanato', uma arte aprendida no tato, realizada principalmente às apalpadelas e por reações parcialmente refletidas em contextos de urgência".

Meirieu (2002), por sua vez, se refere a teorias que se dedicam à análise das necessidades de formação e consideram a possibilidade de que tais necessidades possam ser "isoladas e objetivas", de modo a possibilitar a definição de ações de formação que responderiam exatamente a elas. Esse autor problematiza a ideia implícita de que haveria uma continuidade entre "descrição" e "prescrição":

Simplesmente há problemas que podem ser identificados e cuja resolução jamais está contida na simples análise dos dados, mas sempre requer que o formador formule objetivos e métodos em função de suas finalidades. Definir objetivos de formação é, nesse sentido, aceitar a "insustentável leveza da pedagogia", é recusar criar a ilusão de que basta "ver com clareza" para fazer propostas eficazes, é recolocar a inventividade no centro da conduta formativa, é reencontrar a pedagogia quando uma mecânica tecnocrática tentava extingui-la (MEIRIEU, 2002, p. 269-270).

Ainda com base em Meirieu (2002) e diante das ponderações apresentadas pelos demais autores citados, acredita-se que a atuação docente responde a "ocasiões", que são sempre inéditas e exigem ações rápidas para as quais se recorre à memória em busca de conhecimentos que ajudarão a compor uma solução para cada situação e cuja decisão tomada se constitui em ponto de partida para novas situações que, por sua vez, demandarão novas decisões, em movimento contínuo. Depreende-se que não há modelos mentais prontos para responder às diferentes situações, mas arranjos imediatos formulados a partir de saberes guardados na memória e mobilizados pela situação que se apresenta.

Há, assim, de algum modo, uma dinâmica na qual o professor insere-se para construir-se a si próprio, ao mesmo tempo em que responde às demandas das situações que deve enfrentar. Sua trajetória de identificação desenvolve-se em uma conjuntura que ele consegue retomar, na qual utiliza as dificuldades que deve enfrentar para encontrar seus recursos e inventar uma maneira de reagir. [...] 
Assim, os saberes pedagógicos podem, quando muito, constituir essa "memória" de que fala Michel de Certeau, à qual recorremos quando conseguimos estabelecer entre ela e as circunstâncias esse estranho encontro que ele chama de "ocasião" (MEIRIEU, 2002, p. 271).

Algumas experiências de formação docente têm buscado a constituição de novos "saberes pedagógicos" ao articular teoria e prática a partir do protagonismo dos professores e professoras em formar-se na reflexividade coletiva a partir da própria experiência docente.

Uma experiência dessa natureza é apresentada por Silva (2015), em pesquisa realizada no âmbito do Projeto Políticas de Inclusão Escolar: o atendimento educacional especializado em municípios do Rio Grande do Sul ${ }^{4}$. Este estudo apresenta o projeto desenvolvido em um subgrupo, denominado "Grupo de Práticas", que investe "em um processo formativo instituído pela ação dos professores envolvidos em uma proposta que valoriza a inovação, a experiência docente e a reflexão pedagógica” (SILVA, 2015, p. 58). A vivência do projeto leva a autora a afirmar:

A importância do processo de Retroalimentação conceitual, a partir do qual o grupo reelabora os conceitos percebidos como emergentes, vinculando-os aos seus contextos de trabalho, o que também se relaciona a uma identidade coletiva do grupo. Cabe ressaltar, ainda, a importância da inovação quando pensamos em contextos de inclusão escolar considerando o sentido atribuído ao conceito e que envolve a reinvenção de práticas pedagógicas (SILVA, 2015, p. 108).

Alguns fatores que tornam a proposta apresentada por Silva (2015) uma alternativa potente para a formação docente é a possibilidade de os professores assumirem a sua formação a partir da própria experiência, de fazê-lo de forma cooperativa com seus pares e estabelecer com os textos teóricos um processo de retroalimentação. Tal perspectiva está em conexão com o que Sá-Chaves (2007) chama de passagem do "eu solitário" para o "eu solidário".

\section{CONSIDERAÇÕES FINAIS}

Uma consideração importante, ao se pensar a relação entre os processos de inclusão escolar e a formação de professores, poderia ser ilustrada pela seguinte analogia: não se trata de considerar os professores e as professoras como folhas em branco, onde a formação inicial e continuada produz sua escrita. A análise de produções acadêmicas que discutem a relação entre educação especial, currículo e ação docente mostra que existe uma tendência nas pesquisas sobre o tema que merece ser problematizada, pois a ênfase na responsabilidade docente quanto aos efeitos dos

\footnotetext{
${ }^{4}$ Aprovado pelo Edital de 2012 do Observatório de Educação e desenvolvido pelo Núcleo de Estudos em Políticas de Inclusão Escolar - NEPIE/UFRGS.
} 
processos de inclusão escolar se apresenta como uma simplificação que dificilmente poderia ser respaldada no complexo processo de implementação de políticas públicas, como é o caso das alterações que marcam a educação especial. Essa tendência simplificadora encontra sustentação em premissas que desconsideram a dinâmica social emergente em processos de mudanças: participação, resistências, tendência à conservação, negociação constante...

Ao analisarmos a temática relativa à ação docente, percebemos que estão em pauta, necessariamente, dimensões que a constituem e que exigem não apenas a formação, mas o acompanhamento, a assessoria e o debate que favoreça a ressignificação da escola como instituição. Referimo-nos à necessidade de reconhecer que todos aprendem, sempre; à importância de discutirmos o que efetivamente pode ser identificado como aprendizado; à ruptura com as dinâmicas que traduzem as proposições curriculares em um percurso duplo, separando os alunos em função das expectativas reduzidas associadas àqueles que têm deficiência; ao reconhecimento de que o trabalho docente é ação coletiva e deveria ser pautado no esforço conjunto entre os diferentes profissionais, como o professor de área curricular e aquele com formação especializada em educação especial.

A busca dessas alterações envolveria ações sistemáticas e articuladas, pois se trata não apenas de alterar a dimensão técnica de como se ensina, mas de mudar a cultura que caracteriza os processos escolares em geral. Nesse sentido, a evocação ao longo do texto de um programa como o Observatório da Educação, instituído nas últimas décadas, envolvendo um grande número de universidades brasileiras, nos leva a reconhecê-lo como uma ação que responde em parte a essa grande demanda dirigida à escola brasileira. Ao propor que haja aproximação entre a pesquisa e a prática pedagógica, esse programa instaura também dinâmicas de acompanhamento de processos por meio da atenção aos indicadores de escolarização que deveriam compor com a análise mais singular de contextos específicos. Como foi pontuado pelos autores que contribuíram com a argumentação proposta neste texto, a ciência não se traduz em prática; a prática é forjada pelos "práticos" sob as mais variadas influências. Nesse sentido, é possível conjecturar que os professores não são passíveis de serem formados, mas podem formar-se a si mesmos em diálogo com a ciência e com o contexto em que estão inseridos. 


\section{REFERÊNCIAS}

ALMEIDA, G. P. C.. Representações sociais de inclusão por professores e professoras de Ensino Fundamental. 2012. 96 f. Dissertação (Mestrado em Educação) - Universidade Estácio de Sá, Rio de Janeiro, 2012.

ANJOS, P. T. A. Inclusão escolar de alunos com deficiência: as (im)possibilidades através do olhar de quatro professores de ciências. 2012. 148 f. Dissertação (Mestrado em Educação) - Universidade Estadual Paulista Júlio Mesquita Filho, Bauru, 2012.

ANSELMO, R. D. Inclusão, currículo e formação de professores: uma perspectiva para a formação de Professores/as. 2012. Tese (Doutorado em Educação) - Universidade Federal da Paraíba, João Pessoa, 2012.

ARROYO, M. Ciclos de desenvolvimento humano e formação de educadores. Educação \& Sociedade, ano XX, n. 68, dez. 1999.

BATESON, G. Mente e Natureza. A unidade necessária. Trad. Claudia Gerpe. Rio de Janeiro: Francisco Alves, 1986.

BRASIL. Constituição da República Federativa do Brasil. Brasília: Imprensa Oficial, 1988.

. Lei 9.394, de 20 de dezembro de 1996. Lei de Diretrizes e Bases da Educação Nacional. Lex. Brasília: 1996.

Decreto Legislativo 186, de 09 de julho de 2008. Aprova o texto da Convenção sobre os Direitos das Pessoas com Deficiência e de seu Protocolo Facultativo, assinados em Nova Iorque, em 30 de março de 2007. Diário Oficial da União, Brasília, 10 de julho de 2008a.

Ministério da Educação. Secretaria de Educação Especial (SEESP). Política Nacional de Educação Especial na Perspectiva da Educação Inclusiva. Brasília: MEC/SEESP, 2008 b.

Ministério da Educação. Secretaria de Educação Especial. Decreto 6.571, de 17 de setembro de 2008. Atendimento Educacional Especializado. Lex. Brasília: MEC/SEESP, 2008c.

Decreto 6.949 de 25 de agosto de 2009. Promulga a Convenção Internacional sobre os Direitos das Pessoas com Deficiência e seu Protocolo Facultativo, assinados em Nova York, em 30 de março de 2007. Diário oficial da União, Brasília, n. 163, 26 de agosto de 2009.

Decreto 7.611, de 17 de novembro de 2011. Dispõe sobre a educação especial, o atendimento educacional especializado e dá outras providências. Lex. Brasília, 2011.

CAIADO, K.R.M.; MARTINS, L.S.; ANTONIO, N.D.R. A Educação Especial em escolas regulares: tramas e dramas do cotidiano escolar. Revista Diálogo Educacional, v. 9, n. 28, p. 621-632, set./dez. 2009.

CAMPOS, K.P.B. Isabel na escola: desafios e perspectivas para a inclusão de uma criança com Síndrome de Down numa classe comum. 2012. Tese (Doutorado em Educação) - Universidade do Estado do Rio de Janeiro, Rio de Janeiro, 2012.

CANCLINI, N. G. Diferentes, desiguais e desconectados: mapas da interculturalidade. Trad. Luiz Sérgio Henriques. 3. ed. Rio de Janeiro: Editora UFRJ, 2009.

CARDOSO, A.P.L.B. Políticas de educação inclusiva em tempos de IDEB: escolarização de alunos com deficiência na rede de Ensino no Município de Sobral - CE. 2011. 262 f. Dissertação (Mestrado em Educação) - Universidade Estadual do Ceará, Fortaleza, 2011.

CINTRA, L. M. C. Sentidos produzidos na docência com alunos com necessidades especiais. 2014.92 f. Dissertação (Mestrado em Educação) - Pontifícia Universidade Católica do Rio Grande do Sul. Porto Alegre, 2014.

COSTA, A. L. O. Representação social sobre Educação Inclusiva por professores de Cruzeiro do Sul - Acre. 2009. 229 f. Dissertação (Mestrado em Educação) - Universidade Federal do Rio Grande do Norte, Natal, 2009.

COSTA, V. B. Olhares docentes sobre a inclusão dos estudantes com deficiência na escola comum. Tese (Doutorado em Educação Especial) - Universidade Federal de São Carlos, São Carlos, 2012.

CURY, C. R. J. Direito à Educação: Direito à Igualdade, Direito à Diferença. Cadernos de Pesquisa, n. 116, p. 245262, jul. 2002. 
DANTAS, L. M. "Do que se diz ao que se faz": Práticas Pedagógicas de professores que atuam junto a alunos com deficiência em escola de Horizonte - CE. 2014. 207 f. Dissertação (Mestrado em Educação Brasileira) - Universidade Federal do Ceará, Faculdade de Educação, Programa de Pós-Graduação em Educação Brasileira, Fortaleza, 2014.

DUARTE, C. S. A educação como um direito fundamental de natureza social. Educação \&. Sociedade, Campinas, v. 28, n. 100 - Especial, p. 691-713, out. 2007.

LOPES, E. Adequação Curricular: um caminho para a inclusão do aluno com deficiência intelectual. $2010.166 \mathrm{f}$. Dissertação (Mestrado em Educação) - Universidade Estadual de Londrina, Centro de Educação, Comunicação e Artes, Programa de Pós-Graduação em Educação, Londrina, 2010.

MAGALHÃES, S. M. O.; SOUZA, R. C. C. R. de. A questão do método e da metodologia: uma análise da produção acadêmica sobre professores(as) da Região Centro-Oeste/Brasil. Educação \& Realidade, v. 37, n. 2, p. 669-693, mai./ago. 2012.

MATURANA, H. R.; VARELA, F. J. A árvore do conhecimento: as bases biológicas da compreensão humana. 9. ed. Trad. Humberto Mariotti e Lia Diskin. São Paulo: Palas Athena, 2011.

MEIRIEU, P. A Pedagogia entre o dizer e o fazer: a coragem de começar. Trad. Fátima Murad. Porto Alegre: Artmed, 2002.

MENDES, E. G.; ALMEIDA, M. A.; TOYODA, C. Y. Inclusão escolar pela via da colaboração entre Educação Especial e educação regular. Educar em Revista, Paraná, n. 41, p. 81-93, jul./set. 2011.

MENDONÇA, A. V. Desenvolver potenciais e valorar capacidades: avaliação da aprendizagem de alunos com deficiência intelectual em escolas municipais de Fortaleza/CE. 2014. 144 f. Dissertação (Mestrado em Educação) Universidade Federal do Ceará, Fortaleza, 2014.

MESQUITA, A. M. A. Os elementos de inclusividade na prática curricular de uma professora: uma análise a partir da cultura escolar. 2013. 173 f. Tese (Doutorado) - Universidade Federal do Pará, Instituto de Ciências da Educação, Programa de Pós-Graduação em Educação, Belém, 2013.

ONU. ORGANIZAÇÃO DAS NAÇÕES UNIDAS. Convention on the Rights of Persons with Disabilities. Nova York: ONU, 2007. Disponível em: <http://www.un.org/disabilities/default.asp?navid=15\&pid=150>. Acesso em: 11 mar. 2015.

PLETSCH, M. D. Repensando a inclusão escolar de pessoas com deficiência mental: diretrizes políticas, currículo e práticas pedagógicas. 2009. 239 f. Tese (Doutorado em Educação) - Universidade Estadual do Rio de Janeiro, Rio de Janeiro, 2009.

PLETSCH, M. D.; GLAT, R. A escolarização de alunos com deficiência intelectual em diferentes contextos educacionais. In: 34 ${ }^{\mathrm{a}}$ REUNIÃO ANUAL DA ANPED, 34., 2011, Natal. Anais... Natal: Centro de Convenções de Natal, 2011

SÁ-CHAVES, I. Notas de orientação individual. Pós-doutoramento. Universidade de Aveiro, 2007.

SACRISTÁN, J. G. Tendências Investigativas na formação de professores. In: SILVA, K. A. C. P. C. Articulação teoria e prática na formação de professores: a concepção oficial. Inter-Ação, v. 27, n. 2, p. 1-54, jul./dez. 2002.

SILVA, M. C. Formação Continuada e Educação Especial: a experiência como constitutiva do formar-se. 2015.125 f. Dissertação (Mestrado em Educação) - Universidade Federal do Rio Grande do Sul, Porto Alegre, 2015.

TARDIF, M.; LESSARD, C. O trabalho docente: elementos para uma teoria da docência como profissão de interações humanas. 8. ed. Trad. João Batista Kreuch. Petrópolis: Vozes, 2013.

VASQUES, C. K.; BAPTISTA, C. R. Educação Especial e Processos de Escolarização. Educação \& Realidade, v. 39 , n. 3, jul./set. 2014 . 


\section{RESUMO}

Este texto analisa a escolarização dos alunos com deficiência no ensino comum e sua relação com a atuação docente. Discute-se a política educacional brasileira acerca da inclusão escolar e sua relação com as alterações nos processos de escolarização. A base da reflexão é o pensamento sistêmico associado a uma pesquisa de cunho qualitativo e bibliográfico que analisou as produções acadêmicas brasileiras e a frequente indicação de práticas pedagógicas que não favorecem a inclusão desses alunos, além da ênfase em uma formação dos professores indicada como incipiente. 0 estudo considera a complexidade dos processos de instituição de políticas e sua relação com a dimensão histórica e cultural.

Palavras-chave: Educação Especial. Inclusão Escolar. Escolarização. Pesquisa. Formação Docente.

\section{TEACHING AND SCHOOL INCLUSION - A REFLECTION ON RESEARCH AND SCHOOLING PROCESSES}

\section{ABSTRACT}

This text analyzes the schooling of students with disabilities at secondary school and its relation to teaching. Brazilian educational policy is being discussed in terms of school inclusion and its relation to the changes in schooling processes. The core of this reflection is system thinking associated with to a research of bibliographic and qualitative nature, in which Brazilian academic production was analyzed, as well as some teaching practices which, in spite of being frequently recommended, do not promote the inclusion of these students, and also emphasizes a teacher's training which is seen as incipient. The study takes into account the complexity of the policy implementation processes, as well as its relation to the historical and cultural dynamics.

Keywords: Special Education, School Inclusion, Schooling, Research, Teacher Training.

Submetido abril 2016 Aprovado jun. 2016 